\title{
Decrease of extracellular volume triggers exercise- induced bronchoconstriction to protect the body from water loss
}

\section{Li Yu (D world_yu2000@yahoo.com )}

Beijing IVY Medical Expert League https://orcid.org/0000-0002-0176-3021

\section{Yun Zhou}

Beijing Tiantan Hospital

\section{Research Article}

Keywords: Asthma, Exercise-induced bronchoconstriction, Unconditioned response, Urinary sodium excretion, Extracellular Volume

Posted Date: March 18th, 2021

DOl: https://doi.org/10.21203/rs.3.rs-305345/v1

License: (c) (i) This work is licensed under a Creative Commons Attribution 4.0 International License.

Read Full License 


\section{Abstract}

Purpose: Exercise-Induced Bronchoconstriction describes the narrowing of the airway that occurs during or immediately after exercise. People with Exercise-Induced Bronchoconstriction are very sensitive to both low temperatures and dry air, the physiological mechanism of Exercise-Induced Bronchoconstriction is not very clear. This study aims to investigate the physiological mechanisms of Exercise-Induced Bronchoconstriction in view of the body self-protection response. Methods: The values of the extracellular volume of 23 Exercise-Induced Bronchoconstriction alone compared with the values of 23 healthy adults by comparing the values of their 24-hour urinary sodium excretion, since it is a non-invasive examination. Result: The values of the extracellular volume of the patients were lower than that of healthy adults. Conclusion: We propose that the exercise-induced bronchoconstriction is a kind of an unconditional response that protects the body from water loss, more specifically, the decrease of extracellular volume triggers Exercise-induced bronchoconstriction to protect the body from water loss.

\section{Introduction}

Exercise-induced asthma, or more appropriately exercise-induced bronchoconstriction (EIB) describes the narrowing of the airways that occurs during or immediately after exercise (Ali 2011; Caggiano et al. 2017; Parsons et al. 2013). People who experience EIB are very sensitive to both low temperatures and dry air (Marefati et al. 2015; Anderson SD, Kippelen P. 2011). EIB usually accompanies chronic asthma (Bonini, Palange 2015) and EIB has been in fact reported in 35\% to $90 \%$ of asthmatic patients (Weiler et al. 2007; Crapo et al.1999; McFadden, Gilbert 1994; Wuestenfeld, Wolfarth 2013).

The mechanisms responsible for EIB likely involve multiple mechanistic pathways, here are three popular theories explaining EIB: thermal theories (Chen et al. 1979; Gilbert, McFadden 1992), airway drying (Evans et al. 2005; Argyros et al. 1993), and inflammatory (Hallstrand et al. 2005; Brannan, Turton 2010; Anderson, Kippelen 2008), but the physiological mechanism of EIB is still not very clear.

We think that EIB is mainly caused by the dehydration of the body. In these two coexisted conditions: low extracellular volume (ECV) and relatively dry environment, EIB reduces the expiratory volume (Hildebrand 2011; Hull et al.2016), to reduce the loss of water by breathing. This process protects the body from fast and severe dehydration. We think that EIB is an unconditioned response (UCR).

\section{Materials And Methods}

Study design

All experimental protocols of this study were approved by Beijing IVY Medical Expert League. All methods were carried out in accordance with relevant guidelines and regulations. Informed consent was obtained from all individual participants included in the study. 
From the Aldosterone - Urinary sodium excretion (UNaV) curves (Brunner et al. 1972) and the Aldosterone -ECV curves (Bomback et al.2009; Bomback, Klemmer 2009), we know the lower the UNaV, the lower the ECV. In healthy volunteers (no kidney disease), a salt load should lead to expansion of ECV and resultant suppression of aldosterone.

We could also derive the conclusion from the logical reasoning below:

The lower UNaV $\rightarrow$ means more UNaV were absorbed by the body $\rightarrow$ means lower $\mathrm{Na}$ in the body $\rightarrow$ means lower ECV to keep sodium concentration above the lowest level for normal metabolism, so lower UNaV means lower ECV.

In the study we compare the relative value of the ECV based on the $24 \mathrm{~h} U \mathrm{NaV}$ readings, as the UNaV values are easier to monitor.

\section{Subjects}

Twenty-three subjects aged 23 to 50 years old with physician-diagnosed EIB alone that has no other relevant factors and twenty-three healthy people were recruited, subjects characteristics at baseline are presented in Table 1. Descriptive Statistics Table are presented in Table 2 and Table 3. Subjects who volunteered for the study were currently not taking any diuretics $48 \mathrm{~h}$ prior to the Urine collection; Caffeine/Tea/alcohol and physical exercise was not permitted $24 \mathrm{~h}$ respectively prior to the urine collection. All subjects entered the study on their usual diet before the urine collection. Subjects were excluded if they were pregnant, had a history of other chronic disease.

\begin{tabular}{|lllll|}
\hline \multicolumn{4}{|l|}{ Table 1. Characteristics of study participants } & \\
\hline Variable & Age & Sex & & BMI $(\mathrm{kg} / \mathrm{m} 2)$ \\
\hline Case group & $35.39 \pm 8.17$ & $11(47.8)$ & $12(52.2)$ & $21.00 \pm 1.54$ \\
\hline Health group & $36.13 \pm 6.54$ & $11(47.8)$ & $12(52.2)$ & $21.30 \pm 1.38$ \\
\hline M: Male; F: Female & & & & \\
\hline
\end{tabular}

Table 2.Descriptive Statistics of case group

\begin{tabular}{|llllll|}
\hline & N & Minimum & Maximum & Mean & Std. Deviation \\
\hline Age & 23 & 23.00 & 50.00 & 35.39 & 8.173 \\
\hline BMI & 23 & 18.80 & 23.60 & 21.0000 & 1.53948 \\
\hline Valid N & 23 & & & & \\
\hline
\end{tabular}

Table 3.Descriptive Statistics of Health group 


\begin{tabular}{|llllll|}
\hline & N & Minimum & Maximum & Mean & Std. Deviation \\
\hline Age & 23 & 25.00 & 50.00 & 36.13 & 6.539 \\
\hline BMI & 23 & 18.90 & 23.20 & 21.2957 & 1.38317 \\
\hline Valid N & 23 & & & & \\
\hline
\end{tabular}

\section{Results}

The result indicates that the UNaV of case group was lower than the specified healthy group, the lower $\mathrm{UNaV}$ meant the lower ECV, and so the value of ECV with EIB was relatively low.

\section{Discussion}

This study has shown that ECV was lower in patients with EIB, it means that EIB is related to the dehydration of the body. A latest research (Hannah Marshall et al. 2020) which has proposed that "in healthy adults: i) mild systemic dehydration induced by exercise or fluid restriction leads to pulmonary function impairment, primarily localized to small airways; and ii) systemic, but not local, rehydration reverses these potentially deleterious alterations." also supported our proposal.

From an evolutionary perspective, the organisms get some UCR to adapt to the natural environment and these UCR protect the organisms from injury, such as reaction with skin puncture, coughing, sneezing, shiver, and so on. We think that bronchoconstriction is a kind of UCR. In these two coexisted conditions: low extracellular volume and relatively dry environment, the water loss of the body is reduced by bronchoconstriction, which reduces the exchange of gas, bronchoconstriction reducing the exchange of gas has been proved by hypoxia during an EIB attack, so the bronchoconstriction protecting the body from losing more water. Exercise increases the amount of gas exchange, and may induce sweat, leading to more water loss, so bronchoconstriction will more likely to happen during or after exercising, this being the main reason of EIB. Low ECV may be related to low sodium and high potassium in diet and less water drinking. Several studies (Bar-Yoseph R, et al; Abdullaev AA et al.) supporting our hypothesis gotten from logical reasoning and the necessary experiment have shown that sodium benefits for asthma treatment.

The relationship between temperature and the absolute saturation of the water in the air is shown in the psychrometric chart found on the website of the German Insurance Association (Gesamtverband 2016). In different temperatures, the differences of the amount of water vapor in a parcel of air can be quite large. For example, a parcel of air that is near saturation may contain 39.6 grams of water per cubic meter of air at $35^{\circ} \mathrm{C}$, but only 3.4 grams of water per cubic meter of air at $-5^{\circ} \mathrm{C}$. A typical pair of human lungs contains about 700 million alveoli, producing 70 square meter of surface area (Roberts et al. 2000). Each alveolus is wrapped in a fine mesh of capillaries covering about $70 \%$ of its area (Ochs et al. 2003) and the surface of alveolus is moist (Saladin, Kenneth 2007). So the gas temperature in the lung is near body temperature $\left(37^{\circ} \mathrm{C}\right)$ and the water in the gas is almost saturation. In this situation the moisture content of the gas outside the body is much less than it is in the alveolus, so the more cold and dry it is 
outside, the more body water is lost by breath, the easier bronchoconstriction will occur, this is why people with EIB are very sensitive to both low temperatures and dry air. Fig2 showed EIB flow process.

Cold air will take away heat from body, then the body's skin get goose bumps to decrease heat loss, we think that airway may also shrink to decrease the exchange of air and to decrease the heat lose. This may be another factor that leads to bronchoconstriction. Exercise, nutrition, warmth, and accelerated metabolism will affect this kind of bronchoconstriction.

We analyze: The irritant gas which is harmful to the body will be prevented by bronchoconstriction which reduces the exchange of gas, the bronchoconstriction protects the body from getting afflicted, it is also a kind of UCR and this kind of bronchoconstriction is called occupational asthma. Some harmless allergens considered harmful to the body by the immune system will be reduced by bronchoconstriction, which reduces the exchange of gas, it is also a kind of UCR and this kind of bronchoconstriction is called allergic asthma. This is an error state of the body self-protection mechanism, the cause is not clear, but it may be related with environmental factors, food additives, human milk etc.

A series of bronchoconstriction causing factors overlap together, and this is more likely to increase the degree of bronchoconstriction and exceed the threshold of asthma. The asthma seems to be caused by one factor, but in fact, several factors contribute to this consequence. For example: A modest allergic factor can making bronchoconstriction but may not induce patients with allergic bronchoconstriction to asthma, however, if patients also have the EIB factor, the risk of EIB will be increased.

These modest allergic factors taken individually will increase the degree of bronchoconstriction, but not reaching the threshold causing asthma. When combined together, the EIB factor will accumulate up and exceed the threshold causing asthma. Another example: Exercise increases gas intake. Doing exercise in the irritant or allergic air, bronchoconstriction would occur and it can easily exceed the threshold of asthma and cause an EIB attack. Therefore, the patients that have occupational asthma or allergic asthma are more likely to develop EIB. These different types of asthma are heavily intertwined. If we cure or relieve some types of asthma, other types of asthma can also be reduced.

Although we found that low ECV may be the reason of EIB, we cannot give the exact threshold of ECV, since there are other known or unknown factors that cause bronchoconstriction. For example, ECV is different with different BMI (Bomback, Klemmer 2009); factors like this are hard to quantify and prioritize. As we know, about $32-47 \%$ of total body sodium is in human bones (Forbes 1960), the chronic shortage of sodium in ECV will decrease the sodium in the bones, a part of increased sodium by diets will restore to bones, the process may be slow, and reaching a stable ECV at an appropriate level may need a slow and long process, depending on the patient's specific situation.

From UCR view we think EIB is a body self-protection mechanism for the body and asthma falls under the same category. The paper "Is High Blood Pressure Self-Protection for the Brain?" (Warnert et al. 2016) is from the same protection view. There might be some other diseases that can also be explained based on the body self-defense mechanism. 


\section{Declarations}

\section{Acknowledgments}

We wish to thank Liviu Cosacescu MEng, Ying Huang PhD and XingHuaYang PhD, for their advice on this study and thoughtful comments on drafts of this paper. The authors declare no competing financial interests.

\section{References}

Abdullaev AA, Gadzhiev KM, Eiubova AA. The efficacy of speleotherapy in salt mines in children with bronchial asthma based on the data from immediate and late observations. Vopr Kurortol Fizioter Lech Fiz Kult. 1993 Sep-Oct;(5):25-8.

View in: PubMed

Ali Z. How to diagnose exercise induced asthma? Asian J Sports Med. 2011 Jun;2(2):63-7. PMID: 22375220.

View in: PubMed

Anderson SD, Kippelen P. Airway injury as a mechanism for exercise-induced bronchoconstriction in elite athletes. J Allergy Clin Immunol. 2008 Aug;122(2):225-35; quiz 236-7. doi: 10.1016/j.jaci.2008.05.001.

View in: PubMed

Anderson SD, Kippelen P. Assessment and prevention of exercise-induced bronchoconstriction. $\mathrm{Br} \mathrm{J}$ Sports Med. 2012 May;46(6):391-6. doi: 10.1136/bjsports-2011-090810.

View in: PubMed

Argyros GJ, Phillips YY, Rayburn DB, Rosenthal RR, Jaeger JJ. Water loss without heat flux in exerciseinduced bronchospasm. Am Rev Respir Dis. 1993 Jun;147(6 Pt 1):1419-24. doi:

10.1164/ajrccm/147.6_Pt_1.1419.

View in: PubMed

Brannan JD, Turton JA. The inflammatory basis of exercise-induced bronchoconstriction. Phys Sportsmed. 2010 Dec;38(4):67-73. doi: 10.3810/psm.2010.12.1827.

View in: PubMed

Bomback AS, Klemmer PJ. Interaction of Aldosterone and Extracellular Volume in the Pathogenesis of Obesity-Associated Kidney Disease: A Narrative Review. Am J Nephrol. 2009 Aug; 30(2): 140-146. Published online 2009 Mar 20. doi: 10.1159/000209744. 
View in: PubMed

Bonini M, Palange P. Exercise-induced bronchoconstriction: new evidence in pathogenesis, diagnosis and treatment. Asthma Research and Practice20151:2. doi: 10.1186/s40733-015-0004-4.

View in: PubMed

Bomback AS, Kshirsagar AV, Ferris ME, Klemmer PJ. Disordered aldosterone-volume relationship in endstage kidney disease. J Renin Angiotensin Aldosterone Syst. 2009 December; 10(4): 230-236. doi: $10.1177 / 1470320309352353$.

View in: PubMed

Brunner HR, Laragh JH, Baer L, Newton MA, Goodwin FT, Krakoff LR, Bard RH, Bühler FR. Essential hypertension: renin and aldosterone, heart attack and stroke. N Engl J Med. 1972;286:441-9. doi: 10.1056/NEJM197203022860901.

View in: PubMed

Chen WY, Weiser PC, Chai H. Airway cooling. Stimulus for exercise-induced asthma. Scand J Respir Dis. 1979 Jun;60(3):144-50.

View in: PubMed

Crapo RO, Casaburi R, Coates AL, Enright PL, Hankinson JL, Irvin CG, Maclntyre NR, McKay RT, Wanger JS, Anderson SD, Cockcroft DW, Fish JE, Sterk PJ. Guidelines for methacholine and exercise challenge testing-1999. This official statement of the American Thoracic Society was adopted by the ATS Board of Directors, July 1999. Am J Respir Crit Care Med 161: 309-329 doi: 10.1164/ajrccm.161.1.ats11-99

View in: PubMed

Caggiano S, Cutrera R, Di Marco A, Turchetta A. Exercise-Induced Bronchospasm and Allergy. Front Pediatr. 2017 Jun 8;5:131. doi: 10.3389/fped.2017.00131

View in: PubMed

Evans TM, Rundell KW, Beck KC, Levine AM, Baumann JM. Cold air inhalation does not affect the severity of EIB after exercise or eucapnic voluntary hyperventilation. Med Sci Sports Exerc. 2005 Apr;37(4):544-9. doi:10.1249/01.MSS.0000158186.32450.EC

View in: PubMed

Forbes GB. Studies on sodium in bone. The Journal of P E D I A T R I C S. February 1960 Volume 56, Issue 2, Pages 180-190 doi: 10.1016/S0022-3476(60)80118-7. 


\section{Bar-Yoseph R, Kugelman N, Livnat G, Gur M, Hakim F, Nir V, Bentur L. Halotherapy as asthma treatment in children: A randomized, controlled, prospective pilot study.}

Pediatr Pulmonol. 2017 May;52(5):580-587. Epub 2016 Oct 10. doi: 10.1002/ppul.23621.

View in: PubMed

Gesamtverband der Deutschen Versicherungswirtschaft e.V. (GDV, German Insurance Association). Climate/humidity table. Dec 03, 2016. Available from http://www.tis-gdv.de/tis_e/misc/klima.htm

Gilbert IA, McFadden ER Jr. Airway cooling and rewarming. The second reaction sequence in exerciseinduced asthma. J Clin Invest. 1992 Sep; 90(3): 699-704.doi: 10.1172/JCI115940.

View in: PubMed

Hildebrand Katarzyna. [Exercise-induced bronchoconstriction]. Pneumonol Alergol Pol. 2011;79(1):39-47.

View in: PubMed

Hull JH, Ansley L, Price OJ, Dickinson JW, Bonini M. Eucapnic Voluntary Hyperpnea: Gold Standard for Diagnosing Exercise-Induced Bronchoconstriction in Athletes? Sports Med. 2016; 46: 1083-1093. Published online 2016 Mar 23. doi: 10.1007/s40279-016-0491-3

View in: PubMed

Hallstrand TS, Moody MW, Wurfel MM, Schwartz LB, Henderson WR Jr, Aitken ML. Inflammatory basis of exercise-induced bronchoconstriction. Am J Respir Crit Care Med. 2005 Sep 15;172(6):679-86. doi: 10.1164/rccm.200412-16670C.

View in: PubMed

Hannah Marshall, , Oliver R. Gibson, Lee M. Romer, Camilla R. Illidi, James H. Hull, and Pascale Kippelen. Systemic but not local rehydration restores dehydration-induced changes in pulmonary function in healthy adults. 10 DEC 2020 doi:10.1152/japplphysiol.00311.2020

McFadden ER Jr, Gilbert IA.Exercise-induced asthma. N Engl J Med 330: 1362-1367. doi: 10.1056/NEJM199405123301907. 
View in: PubMed

Marefati H, Vizvari E, Esmaeilizadeh M, Boskabady MH. The effect of climatic conditions on exerciseinduced bronchoconstriction in 10-12 year old students. J Bodyw Mov Ther. 2016 Jul;20(3):549-53. doi: 10.1016/j.jbmt.2015.12.007.

View in: PubMed

Ochs M1, Nyengaard JR, Jung A, Knudsen L, Voigt M, Wahlers T, Richter J, Gundersen HJ. The number of alveoli in the human lung. American Journal of Respiratory and Critical Care Medicine. 169 (1): $120-4$. PMID 14512270. doi:10.1164/rccm.200308-1107oc.

View in: PubMed

Parsons JP, Hallstrand TS, Mastronarde JG, Kaminsky DA, Rundell KW, Hull JH, Storms WW, Weiler JM, Cheek FM, Wilson KC, Anderson SD; American Thoracic Society Subcommittee on Exercise-induced Bronchoconstriction. An Official American Thoracic Society Clinical Practice Guideline: Exercise-induced Bronchoconstriction. American journal of respiratory and critical care medicine 187: 1016-1027. doi: 10.1164/rccm.201303-0437ST.

View in: PubMed

Roberts, M., Reiss, M., Monger, G. (2000) "Gaseous exchange." Advanced Biology. Surrey, Nelson. p. 167.

Saladin, Kenneth S. (2007). Anatomy and Physiology: the unity of form and function. New York: McGraw Hill. ISBN 0-07-322804-4.

Wuestenfeld JC, Wolfarth B. Special considerations for adolescent athletic and asthmatic patients. Open Access J Sports Med. 2013 Jan 10;4:1-7. doi: 10.2147/OAJSM.S23438.

View in: PubMed

Warnert EA, Rodrigues JC, Burchell AE, Neumann S, Ratcliffe LE, Manghat NE, Harris AD, Adams Z, Nightingale AK, Wise RG, Paton JF, Hart EC. Is High Blood Pressure Self-Protection for the Brain?. Circ Res. 2016 Dec 9;119(12):e140-e151. Epub 2016 Sep 26. doi: 10.1161/CIRCRESAHA.116.309493.

View in: PubMed

Weiler JM, Bonini S, Coifman R, Craig T, Delgado L, Capão-Filipe M, Passali D, Randolph C, Storms W; Ad Hoc Committee of Sports Medicine Committee of American Academy of Allergy, Asthma \& Immunology. American Academy of Allergy, Asthma \& Immunology Work Group report: exercise-induced asthma. J Allergy Clin Immunol. 2007 Jun;119(6):1349-58. Epub 2007 Apr 16. doi: 10.1016/j.jaci.2007.02.041

View in: PubMed 
Figures

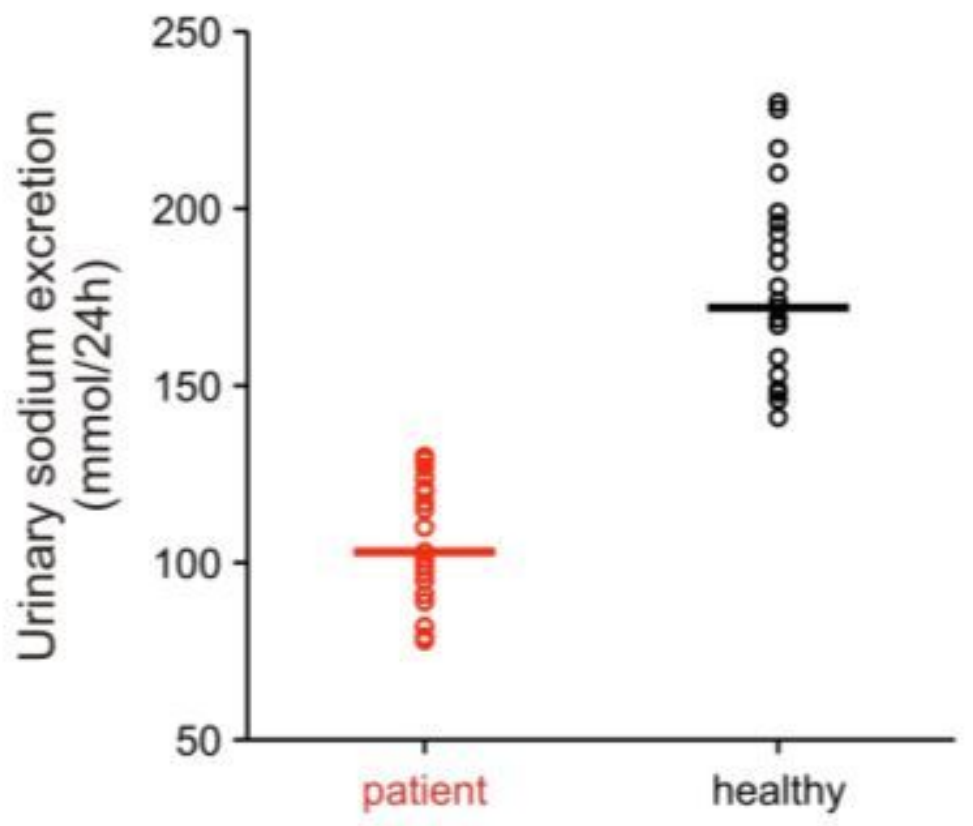

Figure 1

Proposed the comparison of the two group 


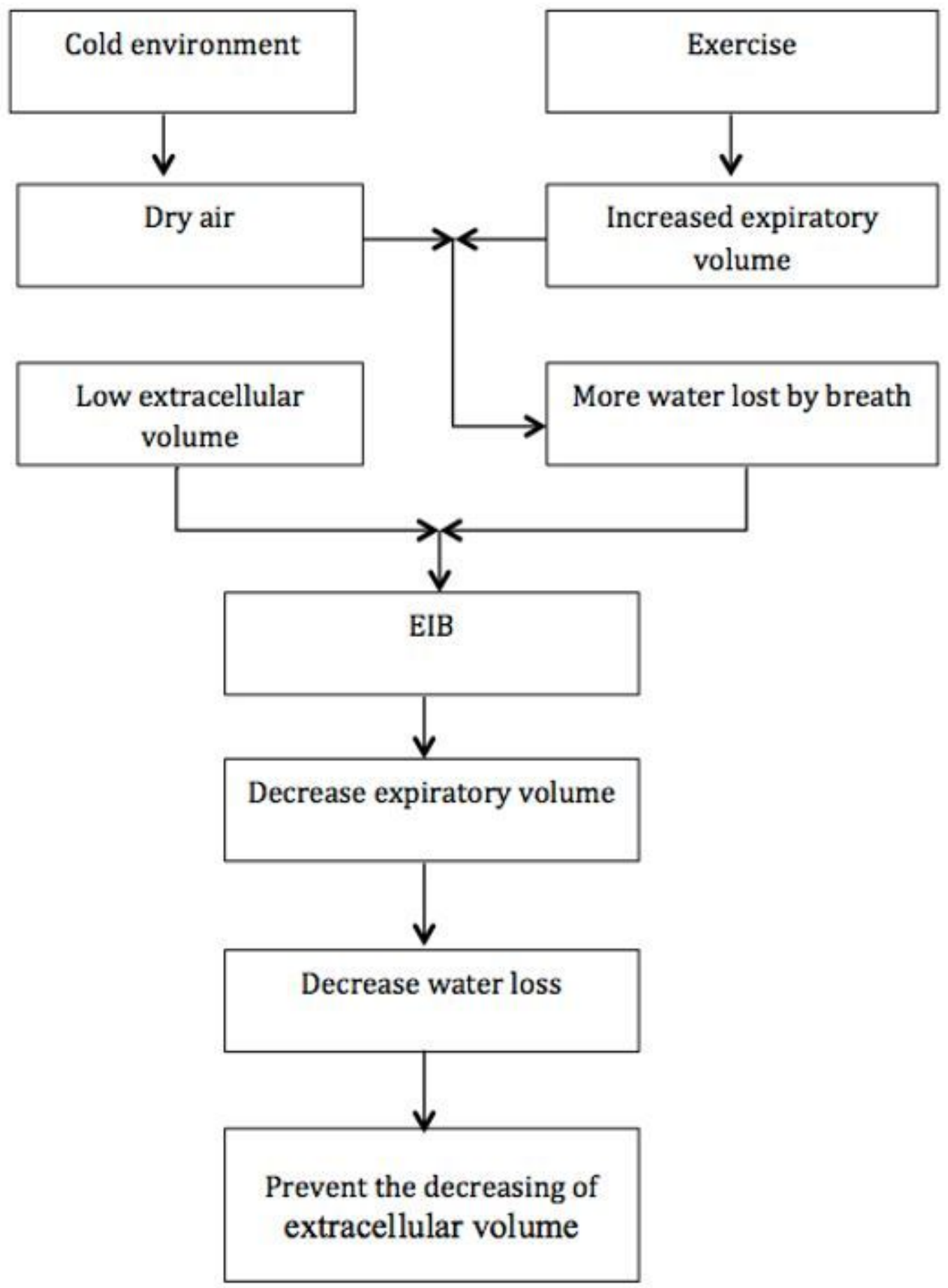

Figure 2

EIB flow process. 